\title{
Educação Física Escolar e Artes Marciais: entre o combate e o debate
}

CDD. 20.ed. 796.017

Walter Roberto CORREIA*

http://dx.doi.org/10.1590/1807-55092015000200337

\section{Resumo}

No Brasil, artes marciais e esportes de combate são considerados conteúdos dos programas de Educação Física do Ensino Fundamental e Médio. Entre outras atividades e tópicos de aprendizagem relevantes, tais como esporte, ginástica, dança, jogos e questões da saúde, as artes marciais e os esportes de combate também foram incluídos no currículo das escolas públicas brasileiras. 0 objetivo deste estudo é analisar as concepções da Educação Física sobre as artes marciais como conteúdo da educação escolar.

Palavras-chave: Educação física; Artes marciais; Esportes de combate.

As Lutas, Artes Marciais e Modalidades Esportivas de Combate (L/AM/MEC) têm alcançado uma visibilidade jamais vista na história da humanidade. Com a expansão das tecnologias da informação e do processo de globalização, essas manifestaçôes estão propulsionadas pelos imperativos da sociedade capitalista e da sociedade do espetáculo. Como um exemplo desse fenômeno, identificamos o empreendimento dos torneios de artes marciais mistas popularmente denominados como "MMA". Em escala global, podemos admitir que as Artes Marciais alcançaram uma projeção de tal ordem, cujas dimensóes lhe conferem um estatuto que transcende o restrito conceito de prática corporal e atividade física. Atualmente pode ser compreendida como um fenômeno político e econômico relevante de ampla e diversa penetração nas mais diversas instâncias da vida social.

Como exemplos, é perfeitamente visível a presença dessas atividades nas esferas das academias, institutos, associaçóes, empresas, mídias, no mercado da indústria e comércio de produtos esportivos, na produçáo literária e, contemporaneamente, nas políticas públicas de esporte, lazer, cultura, saúde e educação. No tocante ao último item, as L/AM/ MEC foram incorporadas como objetos da educação formal com especial destaque para o âmbito da educação escolar. Nesse contexto, temos observado a admissão progressiva dessas manifestaçôes culturais a partir da Educação Física Escolar como a instância curricular responsável pelo trato didático/metodológico desses presumíveis conteúdos formais.
A presença das L/AM/MEC são prescritas, justificadas e sistematizadas a partir de algumas abordagens particulares de ensino que as situam como tema, conteúdo e linguagem da cultura corporal proposto pelo SOARes et al. ${ }^{1}$, além de propostas governamentais que expressam a política de educaçáo de forma mais abrangente, como por exemplo, os Parâmetros Curriculares Nacionais ${ }^{2}$ e a Proposta Curricular de Educação Física do Estado de São Paulo ${ }^{3}$. No âmbito do Ensino Superior, ainda que incipiente, temos a inclusão das L/AM/MEC como objetos de investigação e pesquisa de múltiplas áreas do conhecimento.

No que tange à produção de conhecimento da Educação Física/Esporte sobre as L/AM/MEC, temos alguns estudos sublinhando a necessidade de ampliação e diversificação da produção de conhecimentos, que permitam uma melhor compreensão desse fenômeno para uma inserçáo adequada na perspectiva acadêmica e profissional da área. CoRREIA e FrANCHINI ${ }^{4}$ realizaram um estudo denominado "Produção acadêmica em lutas, artes marciais e modalidades esportivas de combate", cujo propósito foi analisar a produção acadêmica em Lutas, Artes Marciais e Esportes de Combate nas principais revistas acadêmicas de circulação nacional da área de Educação Física. Como resultado desse empreendimento investigativo, foi possível constatar o predomínio dos estudos na área de Biodinâmica (40\%), seguidos pelos Estudos Socioculturais do Movimento Humano (32\%) e Comportamento Motor (8\%). Os estudos aplicados foram divididos em: Pedagogia do Movimento 
Humano (10,7\%), Treinamento Esportivo (8\%), Administração Esportiva (1,3\%) e Adaptação do Movimento Humano (nenhum artigo produzido). Como conclusão, os pesquisadores apontam para as seguintes consideraçôes:

Sendo assim, dada a relevância social das manifestaçôes corporais e de movimento mencionadas por esse estudo, entendemos que a Educação Física pode contribuir com a sociedade a partir de uma intenção deliberada e consciente dos limites e possibilidades do conhecimento que lhe cabe ensejar na direção das "artes de combate", para que superemos os "embates" corporativos, na perspectiva de um "debate" promissor. Como um possível posicionamento propositivo, sugerimos a efetivação de uma aproximaçáo crítico-dialógica do ponto de vista acadêmico e profissional por parte dos múltiplos agentes que dinamizam e reconfiguram as manifestaçóes corporais e de movimento, mais especificamente as relacionadas com L/AM/MEC, a partir do respeito e do reconhecimento dos múltiplos saberes que compóem a "grande teia" expressa pela diversidade cultural. Sem um aporte de conhecimentos críticos e, sobretudo, desprovidos de saberes profissionalmente aplicados, a assertiva e o pleito de uma subordinação das práticas das L/AM/MEC aos ditames corporativos, no nosso entendimento, expressam uma proposição ilegítima (p.7).

Em estudo elaborado por Franchini e Del Vec$\mathrm{CHIO}^{5}$, foi possível sinalizar uma crescente evolução na produção acadêmica relativa ao campo das L/AM/ MEC mesmo se considerando os limitados aportes de recursos destinados para a área em questão. Os pesquisadores destacam a necessidade em se efetivar uma aproximação acadêmica e profissional que poderia ser otimizada a partir de uma interaçáo mais profícua entre os representantes do meio acadêmico com as entidades esportivas e/ou representativas.

Conforme mencionado anteriormente, a produção de conhecimento é uma questão fundamental para uma compreensão e uma intervenção mais legítima da Educação Física com as L/AM/MEC e, sobremaneira, para a incorporação e sistematização dessas manifestaçóes culturais no âmbito da Educação Física Escolar. Essa é uma questão importante na medida que, historicamente, a Educação Física como campo sociocultural e institucional vem admitindo publicamente, por meio das açôes profissionais e corporativas, que seus interlocutores têm as condiçôes necessárias para intervirem e conduzirem uma apropriação junto ao espectro mais amplo das L/
AM/MEC. Essas anunciações são explicitamente postas pelo Conselho Profissional, pelas prescriçóes curriculares provenientes dos processos de formaçáo de bacharéis e licenciados e, nas últimas décadas, nas políticas publicas de educação.

Sendo assim, podemos inferir que está ocorrendo um processo de apropriação dinâmica e controversa da Educaçáo Física com outra instituiçáo ou espectro de manifestaçôes como as L/AM/MEC. Esse processo de "assimilação" e "apropriação" não é nada inédito do ponto de vista da historicidade da Educação Física, basta observarmos e admitirmos como os fenômenos Dança, Atividade Circense, Ginástica, Jogo e Arte Marcial, por exemplo, são anunciadas como temas da cultura corporal e, portanto, da Educação Física contemporânea. A conjectura subjacente do presente ensaio é a de que a diferenciação institucional deve ser considerada para efeito de um melhor posicionamento da Educação Básica e da Educação Física Escolar com as L/AM/MEC na perspectiva de tornar essas últimas em objeto e conhecimento sistematizado da escolarização. Dito de outra maneira, é preciso admitir inicialmente que Educação Física e Artes Marciais são fenômenos distintos para vislumbrarmos qual seria a melhor configuração curricular a oferecer ao campo da educação formal.

Se a hipótese aventada por essas assertivas tiverem alguma pertinência, se torna oportuno destacar a tendência em se estabelecer "leituras" e significaçôes muito particularizadas e enviesadas no referido processo de assimilaçáo e apropriaçáo institucional. Uma tendência claramente observável, é a inclinação dos atores e protagonistas da Educação Física converterem os fenômenos Dança, Jogo e Arte Marcial em atividade física/exercício físico sob o ideário da saúde ou da esportivizaçáo. Nessa perspectiva, a Educação Física e o Esporte tendem a ignorar uma gama significativa de propriedades e elementos inerentes à historicidade própria dos universos lúdicos, gímnicos, rítmicos, expressivos, artísticos, folclóricos, religiosos, estéticos, marciais, etc.

Portanto, sob esse prisma, convém considerarmos as ponderaçôes de Landgraf GonÇALVES e Santos da SiLva ${ }^{6}$, cujo estudo se deteve na análise das concepçóes e definiçốes promulgadas pela Educação Física e pelo Esporte nas tentativas de apreenderem os significados das L/AM/MEC:

Ao reconhecer a dimensão que a discussão sobre este tema assume nos textos acadêmicos, é possível suspeitar que a diversidade de significações não se restrinja à disputa de legitimidade entre as concepçôes apresentadas. Além de dar visibilidades às Artes 
Marciais e às Lutas, os artigos apresentam outras formas de olhá-las e as constituem enquanto um saber a ser apropriado por diferentes perspectivas do universo científico. Dessa forma, considerar as artes marciais e as lutas como formaçóes discursivas em concorrência indica ativação de um campo de batalha discursivo no qual essas práticas corporais são constituídas. Através dos conhecimentos produzidos sobre elas essas práticas se constituem enquanto objeto de saber de modo que possam ser medidas, avaliadas, equiparadas de diferentes maneiras e aos poucos produzem verdades que se consolidam e orientam não só o que se pode falar e onde falar, como também o modo de agir e de pensar o assunto (p.666).

Retomando a questão da inserção das L/AM/MEC como objetos da educação escolar e considerando que esse campo da cultura será mediado pelas "lentes" da instituição Educação Física Escolar, podemos cotejar a necessidade de desafiarmos as ideias, conceitos e representaçóes que emanam dessas interaçóes na perspectiva da escolarizaçáo. Como exemplo dessa complexa dinâmica, o conceito de "Luta" prevalece sobre os conceitos Arte Marcial e Modalidade Esportiva de Combate nos textos das políticas públicas, nas abordagens e tendências de ensino e no mercado editorial bibliográfico. Cabe aqui, também, sublinhar que expressóes jogos de oposição estão sendo admitidos, por vezes, como um termo relacionado ao conteúdo lutas. Mais do que um jogo semântico, as palavras comportam historicidades e mundos vividos a ponto de produzirem práticas sociais muito distintas. Sem grandes investimentos intelectuais e científicos, podemos considerar que o universo das Artes Marciais e das Modalidades Esportivas de Combate transcende os limites e as noçóes inscritas nas denominaçóes luta ou jogos de oposição.

$\mathrm{Na}$ iminência de se estabelecer um diálogo entre instituiçóes antropologicamente distintas, ou seja, Arte Marcial e Educação Física Escolar, caberiam pretensamente nos estreitos e óbvios limites desse trabalho ensaístico, a proposiçáo de problematizarmos o senso comum relativo às L/AM/MEC, de forma a ampliarmos progressivamente a compreensão do objeto de ensino/aprendizagem que, amiúde, queremos deliberadamente incoporar nos contextos e nos domínios dessa prática socioeducativa denominada Educação Física Escolar.

Assim sendo, podemos perscrutar de forma tímida e muito limitada, as representaçóes que temos sobre a natureza e abrangência das L/AM/MEC. Tentar definir esse campo de forma abstrata ou categórica, bem como remeter às origens das L/AM/MEC a um determinado pano de fundo ou gênese comum é demasiadamente arriscado. Comumente ouvimos dizer que as Artes Marciais tem uma origem comum e, recorrentemente, se faz referência ao "Oriente". Sob essas assertivas, podemos indagar qual é o entendimento e a extensão do "Oriente" e, ainda, perguntarmos o que sabemos sobre as manifestaçôes marciais e bélicas construídas no vasto e milenar mundo ocidental. Quando encontramos afirmaçôes categóricas que os sistemas de Lutas ou Artes Marciais possuem a mesma origem, nos inclinamos a uma generalização que nos impede de compreender a magnitude desse campo social. Uma tentativa forçada de submissão de algo plural para um amálgama homogeneizante. Dizer que as artes marciais são provenientes do Oriente e milenares, podem suscitar dúvidas sobre os conhecimentos de quem profere tais afirmaçóes. Nem toda prática milenar se justifica na modernidade. Aliás, teremos sempre na cultura e na educação a árdua tarefa em discernir o arcaico, o tradicional e o moderno para efeito de um posicionamento mais eficaz diante das manifestações socioculturais.

As artes e sistemas de combate em sua pluralidade se deram em contextos políticos muito diferenciados. As demandas sociais que evocaram a elaboração dos saberes e poderes relativos aos conhecimentos e às tecnologias corporais de combate, são questóes ainda a serem consistentemente respondidas pela historiografia contemporânea. As características, as lógicas e os processos de geraçáo, conservação, transmissão e transformação são muito particulares e/ou singulares.

Considerando a extensão dessa complexidade, podemos inferir ou mesmo hipotetizar que, muitas das que chegam aos domínios da cultura contemporânea, não foram elaboradas nas suas gêneses com vistas às sociedades urbanas, industriais e pós-industriais e, tampouco, ao homem da sociedade de direito civil e da globalização. Dito de outra forma, muitos dos seus elementos técnicos, pedagógicos e simbólicos, por exemplo, não foram exatamente produzidos para escolas, universidades, crianças, adolescentes, adultos, idosos, cidadãos e cidadãs com necessidades especiais, pautadas pelos conceitos da medicina e qualidade de vida modernos. Cabe também lembrar que as referidas manifestaçóes corporais vem passando por processos sucessivos e alternados de conservação e transgressão nos seus conteúdos e linguagens ao longo do processo civilizatório. $\mathrm{O}$ princípio da inclusão e da democracia, tampouco, não respaldaram de saída e obrigatoriamente muitas dessas objetivaçóes culturais. Ainda sob esse prisma 
ou questão, as idiossincrasias subjacentes ou inexoráveis às práticas marciais são densas e perpassaram a constituição dessas formas de expressão humana.

Se houver alguma procedência ou validade nessas "assertivas", isso nos remeterá a busca de um zêlo estratégico no trato metodológico desses objetos culturais para a escolarização e para Educação Física Escolar, uma vez que as especificidades e as "vocaçôes" dessas instituições estão repletas de distinções nas suas funções e papéis sociais. Explicitando de maneira mais premente, as finalidades, os processos e conteúdos não se alinham ou se coadunam, necessariamente, sob os parâmetros e as discursividades pautadas na atividade física para promoção da saúde e do esporte como ferramenta de inclusão social. Essas últimas são possibilidades factíveis, especialmente considerando que as mediaçóes pedagógicas e sociais estáo condicionadas à qualidade dos saberes e poderes dos seus protagonistas, mas não estáo necessariamente garantidas. Em que pese, porventura, as ponderaçóes e ênfases aqui postadas, não excluímos a riqueza, a relevância e a pertinência dessas construçóes culturais como objetos de socialização escolar.

Ainda sob a intencionalidade em desafiarmos o senso comum atribuído ao campo das L/AM/ MEC, podemos problematizar algumas assunçóes relacionadas às suas presumíveis "positividades". A potencial "positividade" dessas práticas são factíveis, no entanto, o que não interessa são as pressupostas "positividades" generalizantes e universais cunhadas nos estreitos limites dos corporativismos. Um face dessa tendência diz respeito ao papel "positivo" e "inerente" do estatuto filosófico nas L/AM/MEC como um provedor de qualidade intrínseca.

A título de exemplificação, retomamos a ideia de que as Lutas e Artes Marciais são, em "tese", portadoras de uma orientação filosófica. Invariavelmente, podemos subentender que essas afirmaçóes tendem a sugerir que a presença de um corpo filosófico de fundo ratificam uma prática bem orientada ou benéfica aos seus praticantes. Inicialmente, reconhecendo a ousadia e a impertinência das palavras que se seguem, podemos nos remeter as consideraçóes de $\mathrm{CHENG}^{7} \mathrm{e}$ JuLlien $^{8}$ que, como sinólogos, ou seja, estudiosos da cultura chinesa, destacam que a Filosofia representa o logos grego e, em comparação do que se produziu históricamente na própria cultura clássica chinesa, seria mais apropriado nos referirmos às tradiçóes e/ou forma de pensamento. Entretanto, podemos admitir sem grandes angústias de que as L/AM/MEC são passíveis de se submeterem ao crivo do pensamento arguidor, investigador, radical, profundo, que busca as essências das coisas e seus significados a partir da rigorosidade epistemológica, ou seja, passíveis de serem abordadas filosoficamente. Não seria demasiado relembrar que, para que algo seja significativo ou relevante, náo necessitamos de uma autorização filosófica prévia para a experiência e para vivência.

Outra construção alicerçada no senso comum insinua que às práticas orientais levam os seu praticantes para atitudes e virtudes transcendentais, pacifistas e espiritualizadas. Como provocação, mas não como insulto, ao admitirmos essas ilações como verdadeiras, estamos muito possivelmente atrelados a um reducionismo no que tange à condição humana e, sobretudo, uma explícita deferência ingênua de cunho exótico e exotérico.

Portanto, conjecturamos que a premissa de uma doutrina filosófica inexorável às L/AM/MEC é passível de questionamento, desde a sua efetiva presença quanto aos supostos benefícios. $\mathrm{O}$ que comumente observamos é a validação de certos princípios, valores e éticas muito particulares e contingenciais defendidas pelos protagonistas das múltiplas escolas, estilos, modalidades de práticas ou sistemas marciais. É razoável admitirmos que um manejo sapiente e tutorial de mestres e professores na condução de experiências marciais podem, de fato, favorecer o desenvolvimento humano. No entanto, a simples nomeação de instrutor, professor, técnico, graduado, mestre ou tutor, não nos permite aferir a qualidade do processo de formação e atuação desses atores sociais.

Por vezes, muitas contradiçôes e precariedades ficam ocultas sob as titulaçôes. A titularidade e a legalidade não são necessariamente soberanas sob a égide da legitimidade do notório saber! Dito de outro modo, ser professor, faixa preta ou campeáo da modalidade "X" diz algo mas, obviamente... não diz tudo. Autoridade e autoria tutorial e pedagógica implica um nível sofisticado de saberes. Habilidades e excentricidades motoras e corporais não qualificam alguém para uma apropriada pedagogia da "experiência marcial" como ferramenta de desenvolvimento e promoção humana.

Por essa razão, pensar mais detidamente sobre elaboraçôes técnicas como golpes de percussão, chaves, torçôes, estrangulamentos e projeçóes, por exemplo, exigem uma melhor contextualização na perspectiva dos objetivos da Educação Física Escolar e da "Escola Cidadâ". Temos testemunhado que muitos dos protagonistas do cenário cultural marcial remetem seus esforços no sentido de atualizarem os conteúdos, as linguagens e os expedientes 
didáticos. Entretanto, a pluralidade e a diversidade de concepções promovem consensos e dissensos bastantes discrepantes. Dar-se conta da diversidade é dar-se conta da desigualdade de saberes e poderes. No contexto de cada modalidade ou sistema de L/ AM/MEC, a desigualdade produz reverberaçóes na qualidade da própria vitalidade e validade de uma dada manifestação cultural. Os saberes e conteúdos só tem sentido se forem passíveis de transmissáo qualificada e situada numa determinada conjuntura social e antropológica. Para o processo de sistematização das intençôes educativas na e da escola, na e da Educação Física, essas questōes não são irrelevantes, especialmente quando temos a intenção em legitimar as L/AM/MEC provenientes do contexto "não escolar" para o seio da organização curricular.

Seguindo no exercício da problematização do senso comum relativo às L/AM/MEC, destacamos uma outra e importante noção que diz respeito à questão da defesa pessoal. Sobre essa ideia, podemos identificar uma premissa de que essas práticas podem implicar uma condição de relevância e eficácia para a proteção do indivíduo perante o fenômeno da violência social. Em que pese a possibilidade de se mobilizar um conhecimento técnico elaborado a ser empregado numa situação premente de risco e agressão, as limitaçóes e as possibilidades desses recursos ou habilidades são perfeitamente discutíveis.

Como indagação sobre essas expectativas, seria oportuno destacar que usualmente os programas e propostas de defesa pessoal sáo orientadas sob o prisma do desenvolvimento de técnicas para uso pragmático em diferentes situaçôes de confronto ou combate corporal. Nesse sentido, o enfoque dessa "competência" está ancorada na dimensão da remediaçáo, ou seja, no lidar com o conflito já estabelecido em amplo processo de fluxo e transformação. Dessa maneira, as questôes da prevenção e do manejo do pós-evento, ou seja, após uma ocorrência, não são objetos de estudo ou apreciação. Quando nos pautamos no paradigma do tecnicismo, nos escapa que cada cenário emergente de crise é dotado de um processo evolutivo em condiçôes ambientais e pessoais significativamente cambiantes. Portanto, ainda que consideremos um valor importante da racionalidade técnica no contexto do "self defense", se torna imperioso relembrar que para cada movimento ou dispositivo técnico corporal ele deve ser mobilizado a partir de um contexto.

As Lutas e as Artes Marciais foram forjadas a partir de demandas socioambientais muito específicas, cuja configuração técnica tem no seu bojo limites e possibilidades muito singulares. Dito de outro modo, não é possível propor soluçóes simples para problemas complexos. Cabe aqui destacar que o significante "defesa pessoal" é um dispositivo muito assimilado pela população em geral, sobretudo, quando temos um quadro patente de violências nas mais distintas esferas da vida cotidiana. BAUMAN ${ }^{9}$ destaca que a indústria e o mercado da segurança está respaldada pela ideologia do medo líquido amplamente veiculada e manejada por interesses políticos e corporativos. As L/AM/MEC se inserem ambivalente e contraditoriamente nesse quadro.

A construçâo ideológica do medo sobre a subjetividade humana é altamente potencializada por meio da linguagem e do ideário da defesa pessoal que, por sua vez, encontra uma abertura favorável para se inserirem como demandas na política de segurança pública e individual. Como sintoma desses processos, é recorrente que as angústias do mundo adulto se projetem sobre as crianças e jovens, especialmente, quando pais e educadores encaminham seus filhos e alunos para programas dessa natureza com a pretensão de lhes oferecer mais "segurança". A pergunta que se impóem é: segurança de quem? A defesa pessoal não fica circunscrita aos interesses dos protagonistas das modalidades e sistemas de Lutas e Artes Marciais, mas tomam a preocupação das instituiçóes educacionais. As formas de violências intra e extra muros escolares produzem apreensóes contumazes sobre a percepção dos educadores em geral. $\mathrm{Na}$ incapacidade de compreenderem e lidarem com um fenômeno dessa magnitude e complexidade, as comunidades educativas ficam suscetíveis aos múltiplos diagnósticos disponíveis e, por sua vez, por açôes oportunistas.

Não podemos ignorar a dramaticidade das taxas de mortalidade infantil e juvenil presentes na atual conjuntura brasileira. A escola está diretamente sensível uma vez que concomitantemente ela é vítima e algoz de certas manifestaçóes de violência humana. Entretanto, as faces desse fenômeno ultrapassam as "caricaturas" desenhadas pelo senso comum, especialmente, no que tange às suas causas e efeitos e, por essa razão, nos interpõe a dúvida sobe a presumível efetividade dos cursos de defesa pessoal perante um cenário social complexo.

Prosseguindo pelo interior das escolas, com o advento do "bullying", vozes mais "altivas" se pronunciaram na pretensão do oferecimento de programas de Artes Marciais como forma de "solução" do problema. A presença crescente de cursos de L/AM/MEC no interior das instituições educativas, vem se inscrevendo nesses espaços educativos como atividades e cursos 
extra-curriculares para as comunidades escolares, incluindo-se nessa realidade a oferta dessas práticas para a educação infantil. Um questão impertinente se apresenta: com que propósito?

Ensejar reflexôes de como evitar situações de risco, prevenir acidentes, amenizar o potencial de conflitos nas relaçôes pessoais ordinárias e controlar o narcisismo pessoal como "detonador" da agressividade desmedida podem, sob certas circunstâncias, serem mais eficazes do que socos, chutes, estrangulamentos ou torçóes. Essas estratégias transcendem a perspectiva técnica e utilitária e não são comumente mobilizadas com a devida pertinência. Não seria um devaneio considerar que antes de uma "violência vermelha" (lesóes corporais evidentes e contundentes) essa mesma é precedida de uma "violência branca” (simbólica, ofensiva, desrespeitosa etc...).

Se houver alguma ligação de fidelidade dessas presunçôes argumentativas com a realidade, não seria de todo inútil aventar a proposiçáo do um conceito de "defesa pessoal ampliada", que perpassaria por questôes como a tomada de consciência do potencial de risco em diferentes contextos de convivência, inserindo a aprendizagem de avaliação de cenários e, até mesmo, a elaboração de habilidades corporais de combate preventivos e paliativos. Sendo assim, o conceito ordinário de defesa pessoal ampliaria seus horizontes ou fronteiras na perspectiva da defesa e valorizaçáo da vida.

Associada às questóes acima mencionadas temos, também, o que podemos denominar de senso comum pedagógico, ou seja, aquele partilhado entre os educadores e educadoras por contingência do fluxo ordinário do cotidiano sem uma reflexão mais cuidadosa sobre seus fundamentos ou demandas. Podemos identificar algumas assunçóes proferidas por professores e professoras de Educação Física quando estấo na incumbência de sistematizar e prover os alunos de conhecimentos e experiências com as L/AM/MEC.

Um entendimento muito generalizado sobre o processo de tematização curricular das L/AM/ MEC na perspectiva dos professores e professoras de Educação Física é a preocupação de que essas mesmas se constituam em dispositivos de violência escolar. Não é raro evidenciarmos as assunçóes pronunciadas ou contidas na opiniáo pública entremeando as Lutas e Artes Marciais como práticas agressivas e violentas. Entretanto, longe de exaurir essa questão, podemos indicar a possibilidade da dúvida sobre essas pronunciaçóes. A agressividade é um componente da condiçâo humana relevante para o processo de adaptação, interação e transformação da vida. Em que pese que a agressividade seja um componente inerente à violência, podemos empreender um juízo de que essas duas noçóes não são equivalentes ou sinônimos. A violência tem implicaçôes éticas, morais e são dotadas de valoração e simbolização cultural. Esse fenômeno implica um espectro de manifestaçóes que são produzidos e avaliados conforme o quadro de referência sociocultural. $\mathrm{O}$ que pode ser violência para um grupo ou sociedade náo é necessariamente para outros. A admissão imediata de que a experiência corporal de combate desencadeia inequivocamente comportamentos violentos é passível de questionamento. A escola como instância de mediação da diversidade humana nos seus tempos e espaços próprios, tem uma disponibilidade muito precária para dar orientação e direcionamento à agressividade dos seus protagonistas e, portanto, é compreensível que tome essa virtude humana como sinônimo de violência. Como manejamos mal os conflitos, temos certo que nos perdermos em confronto.

Outro aspecto incorporado à discursividade docente è a de que a inserção eficaz das L/AM/MEC na escola está condicionada à experiência prévia dos professores e professoras com as práticas desse universo. Argumentos como "eu nunca fiz luta" e "não sou lutador" são recorrentes como negação dessas atividades no tocante ao ofício docente. Ainda sob esse aspecto, também agrega-se o argumento de que "não faço" porque "não gosto!" Ainda que consideremos que os conhecimentos prévios possam de fato oferecer referências para constituição dos saberes docentes, a iniciativa e a disposição em buscar subsídios está sempre dada. Os professores e professoras já têm historicamente empreendido esforços na construção de conhecimentos para si mesmos junto aos outros componentes da cultura corporal (Danças, Esportes, Jogos, Ginásticas, Exercícios Físicos etc.) de maneira processual, gradativa e permanente.

Se a Educação Física Escolar tem o mérito e o desafio em ter como objeto de ensino e aprendizagem essa grande "teia" de manifestaçôes culturais como referência, seus protagonistas inevitavelmente devem entender que a apropriaçáo dos saberes da cultura de movimento é tarefa para toda a carreira docente. Além desses aspectos, seria oportuno a proposição de uma questão fundamental: É desejável ensinar "Lutas" na escola? Ensinar a "lutar" na Educação Básica? Quais seriam as implicaçôes de uma proposição dessa natureza? Não nos parece razoável aceitarmos essas premissas passivamente, inclusive, por presumirmos que nos encontramos num estágio muito rudimentar de entendimentos dessa interlocuçáo institucional entre Escola, Educação Física Escolar e L/AM/MEC. 
Contudo, mesmo sem estabelecermos contornos definitivos para essa problemática, podemos ousar em propor que os papéis da escola e do componente curricular Educação Física sejam tematizar e pedagogizar o fenômeno das L/AM/MEC a partir dos interesses da educaçáo formal.

Assim sendo, a noção de mediação transcende a de instrutor de programas de Lutas e Artes Marciais na escola. É a função social da educação escolar, articulada à especificidade da Educação Física, que devem condicionar a transformação didática e pedagógica dos objetos de ensino e aprendizagem. São os propósitos da escola que norteiam a maneira pela qual as L/AM/ MEC serão conservadas/transformadas para efeito de uma legitimidade educativa. PÉrez Gomes e SACRISTÁN $^{10}$ ao discutirem a função social da escola, destacam que a seleção e a estruturação das intenções educativas implicam uma dinâmica que comporta processos de conservação e transgressão dos conteúdos escolares. Aqui não basta a reproduçáo dos objetos da cultura que serão configurados em conteúdo disciplinar mas, principalmente, submetê-los ao crivo da problematização. Aqui o item da rigorosidade epistemológica no trato dos saberes escolares é essencial.

O papel das experiências de movimento no interior da aula deve privilegiar a experienciação exploratória e não a instrumentalização técnica ou marcial propriamente dita. Além da perspectiva de prover os alunos de conhecimentos procedimentais, adicionamos a possibilidade em tematizar as L/AM/MEC do ponto de vista político, histórico, psicológico, sociológico, ecológico, estético, biodinâmico etc; a mediação pedagógica pode e deve se assentar sobre a articulação com outras disciplinas de forma a otimizar a transversalidade inerente ao fenômeno das L/AM/MEC. Essa possibilidade está de saída autorizada, principalmente, quando não tomamos como núcleo das intençôes educativas o "saber lutar" e percebemos, principalmente, a magnitude e riqueza simbólica das práticas marciais. Vale apena mencionar que lutar e viver têm muitas coisas em comum! $\mathrm{Na}$ expressão da linguagem do combate simbólico, o sentir, o pensar e o agir estáo todos enraizados na condição de existência.

Ainda sob às construçôes do senso comum, sublinhamos uma expressão não muito incomum do tipo: "não gosto e não me interessa trabalhar com as Lutas". Perante essa anunciação, podemos desafiar impertinentemente essa noção na medida que fazer "o que gosta" e "o que interessa" não se circunscrevem coerentemente nos domínios da autonomia docente. A responsabilidade docente convoca cada professor e professora para que reavalie sua relação com o objeto de ensino e aprendizagem. É evidente que as demandas da profissionalidade docente devem abrigar não apenas as condiçóes econômicas e materiais que são insuficientes para muitos educadores e educadoras mas, estrategicamente, temos que dispor de alternativas para a construção colegiada e partilhada dos saberes necessários à prática educativa. A recusa imediata e injustificada por parte de alguns docentes em se envolver com certas demandas curriculares, pode ser entendida como um espontaneísmo inconsequente. Paulo FreIrE ${ }^{11}$ anunciou em suas memoráveis reflexôes que a humildade pedagógica nos permite compreender que ninguém é ignorante de tudo e, tampouco, ninguém sabe tudo. Ninguém educa ninguém...nos educamos reciprocamente! Contudo, a visão Freireana nos lembra sobre a necessidade ética de nos rersponsabilizarmos sobre nossa prática e sobre a nossa práxis docente.

Outro argumento presente nos domínios do senso comum pedagógico diz respeito à precariedade em que as L/AM/MEC são ofertadas e, sobremaneira, tratadas, no processo de formação inicial (Licenciaturas). Expressôes como: "não tive aulas de Lutas" ou "as aulas foram muito ruins ou limitadas", também são apontadas como um fator de restrição para o encorajamento dos docentes no processo de apropriação das L/AM/MEC como conteúdos escolares. Não podemos considerar esses argumentos como algo desprezível ou irrelevante. Todavia, admitindo a possibilidade dos múltiplos espaços de informação que podem ser mobilizados ao longo da formação continuada/permanente, podemos relativizar a dimensão imobilizadora e fatalista dessa queixa. Tendo em vista que uma carreira docente pode alcançar uma vitalidade de 25 a 30 anos, a questáo da graduação (três ou quatro anos) náo pode ser tomada como um fator unívoco ou restritor.

Concluindo, podemos reconhecer que as L/AM/ MEC estão grávidas de relevância social e são dotadas de pertinência como objetos da cultura escolar. Os seus impactos econômicos, sociais, políticos e, especialmente, sociocomportamentais, justificam o interesse e as interfaces dessas objetivaçôes culturais como elementos e conteúdos a serem transformados/ assimilados pelos propósitos e finalidades das instituiçôes científicas e educativas. $\mathrm{Na}$ esfera ou domínio da escolarizaçáo, essas manifestaçóes têm logrado um lugar no âmbito das políticas públicas e, dentre essas, a educação. A Educação Física Escolar tem se constituindo como um dispositivo curricular premente para a configuração das L/AM/ MEC como objeto e conteúdo da sistematização dos 
saberes docentes e discentes. Assim sendo, por se tratar de uma articulação entre instituiçóes distintas, ou seja, Educação Física Escolar e L/AM/MEC, devemos envidar esforços para construirmos uma trajetória mais eficaz de aproximação acadêmica e profissional com essas áreas e, sobretudo, desafiarmos as concepções ainda prematuras e incertas (senso comum) que detemos sobre essa relaçáo que, certamente, poderá ser profícua para o campo da cultura e da educação formal.

\begin{abstract}
Physical Education at School and Martial Arts: between fighting and debate

In Brazil, martial arts and combat sports are considered subjects of Physical Education programs in lementary/high schools. Among other relevant activities and learning topics such as sports, gymnastics, dance, games and body health issues, martial arts and combat sports have also been included in the Brazilian public schools curriculum. The aim of this study is to analyze the conceptions from the Physical Education area about martial arts as a subject in the school education.
\end{abstract}

KEY WoRDS: Physical education; Martial arts; Combat sports.

\title{
Referências
}

1. Soares CL, Taffarel CNZ, Varjal E, Castellani Filho L, Escobar MO, Bracht V. Metodologia do ensino de educação física. São Paulo: Cortez; 1992.

2. Brasil. Ministério da Educação e Cultura. Parâmetros curriculares nacionais (ensino fundamental): educaçáo física. Brasília: SEF; 1997.

3. São Paulo. Secretaria de Educação. Proposta curricular do Estado de São Paulo: educaçáo física. São Paulo: SE/CENP; 2008.

4. Correia WR, Franchini E. Academic papers about fights, martial arts and combat sports. Motriz. 2010;16:1-9.

5. Franchini E, Del Vecchio FB. Estudos em modalidades esportivas de combate: estado da arte. Rev Bras Educ Fís Esporte. 2011;25 N espec:67-81.

6. Gonçalves AVL, Santos da Silva MR. Artes marciais e lutas: uma análise da produçáo de saberes no campo discursivo da educação física brasileira. Rev Bras Ciênc Esporte. 2013;35:657-71.

7. Cheng A. História do pensamento chinês. Petrópolis: Vozes; 2008.

8. Jullien F. Tratado da eficácia: São Paulo: Editora 34; 1998.

9. Bauman Z. Medo líquido. Rio de Janeiro: Zahar; 2007.

10. Sacristán G, Perez Gomes AI. Compreender e transformar o ensino. Porto Alegre: Artmed; 2007.

11. Freire P. Pedagogia da autonomia: saberes necessários à prática educativa. São Paulo: Paz e Terra; 2007.

\begin{tabular}{r|r} 
ENDEREÇo & \\
Walter Roberto Correia & \\
Escola de Educação Física e Esporte - USP & Recebido para publicação: 02/04/2015 \\
Av. Prof. Mello Moraes, 65 & Aceito: 04/05/2015 \\
05508-030 - São Paulo - SP - BRASIL & \\
e-mail: wr.correia@usp.br &
\end{tabular}

